Original Article

\title{
ASSESSMENT AND COMPARISON OF INJECTION TECHNIQUES USING MANNEQUIN AS A LEARNING TOOL AND OSPE AS AN EVALUATION METHOD
}

\author{
SARITA PANIGRAHY, SUNIL KUMAR PANDEY*, MEHER SHEENA, BALA TRIPURA SUNDARI
}

Department of Pharmacology, Gayatri Vidya Parishad Institute of Healthcare and Medical Technology, 6-25 Maridi Valley, Marikavalasa, Madhurwada, Visakhapatnam-48, Andhra Pradesh, India

Email: sunilmanipal@gmail.com

Received: 16 Jul 2021, Revised and Accepted: 07 Sep 2021

ABSTRACT

Objective: The aim of the current study was to compare the effectiveness of only demonstration and demonstration coupled with the powerpoint method (intervention) in acquiring the knowledge of injection technique using objective structured practical examination (OSPE) as an evaluation tool.

Methods: The present study was conducted among I $^{\text {nd }}$ professional medical undergraduates $(\mathrm{N}=80)$. Identification of medical devices, parts of a syringe and intravenous (IV) infusion set, intramuscular (IM) injection and intravenous infusion techniques were taught using demonstration and intervention method. Participants were then evaluated for their knowledge by OSPE method using validated checklists. Participants were also asked to give feedback for the teaching and evaluation method. Data were analyzed using SPSS 20.0.0, IBM Corporation.

Results: After the intervention method $100 \%$ participant could identify needle, cannula, and IV infusion set. Noticeable difference was found in identifying parts of a syringe and IV infusion set after intervention method. OSPE evaluation post-intervention showed that more number of participants could perform the steps of injection correctly and in sequence. OSPE scores post-intervention differed significantly $(<0.001)$ with demonstration method.

Conclusion: Demonstration coupled with the powerpoint teaching method was found better than the demonstration method alone. This method should be used to impart practical knowledge of injection technique.

Keywords: Skill, Practical, Demonstration, Simulation

(C) 2021 The Authors. Published by Innovare Academic Sciences Pvt Ltd. This is an open access article under the CC BY license (https://creativecommons.org/licenses/by/4.0/) DOI: https://dx.doi.org/10.22159/ijpps.2021v13i11.42756. Journal homepage: https://innovareacademics.in/journals/index.php/ijpps.

\section{INTRODUCTION}

An injection is the administration of a therapeutic, preventive and diagnostic agent into the body using a needle and a syringe. As defined by WHO (World Health Organization), "a safe injection does not harm the recipient, does not expose the provider to any avoidable risks, and does not result in waste that is dangerous to the community [1]."Blood-borne infections like HIV (Human Immunodeficiency Virus), HBV (Hepatitis B virus), and HCV (Hepatitis C Virus) are few examples of unsafe injection practices [1, 2]. A mannequin simulation is an easiest and safest way to learn and practice different routes of parenteral administration without harming human volunteers [3]. In a similar fashion, OSPE evaluation has come a long way and proved to be an effective method of evaluation [4]. Evaluation of practical knowledge should be based on the skills of students and not just on theoretical knowledge. The same thing has been emphasized in newer competency-based MBBS (Bachelor of Medicine and Bachelor of Surgery) curriculum [5].

This study was meant to assess and compare the knowledge and skills of students after demonstration on mannequins with or without powerpoint explanation. It will help us to decide whether the demonstration method would be continued or intervention method has to be adopted as our training method. If these techniques are being demonstrated on mannequins at an early phase of the student's medical course, it will boost their confidence level and decrease their anxiety, fear in performing skills directly with real patients, and also enables them to perform less medical risk in clinical settings and communities.

\section{MATERIALS AND METHODS}

\section{Study design}

This was a cross-sectional, observational study. After obtaining consent of the Institutional Ethics Committee of our institute, the project was initiated in accordance with the prepared study protocol. All the students of second-year medical undergraduates of our college were included after taking the due informed consent. The total duration of the study was approximately $3 \mathrm{mo}$.

\section{Methods of teaching}

Standard operating procedure for the performance of two parenteral routes of drug administration

The faculties of pharmacology discussed the steps to be followed in setting up the hand mannequin and simultaneously prepared step by step process to perform the injection techniques of two routes (IM and IV infusion). Based on this, OSPE checklists were prepared. The checklists were validated by a team involving two pharmacologists, a faculty each of anaesthesia, Casualty medical officer and a nurse. Handouts containing general guidelines for parenteral administration of drugs (IM and IV infusion), parts of a syringe, needle, and iv infusion set were printed and distributed to all the participants.

\section{Execution of methodology}

Teaching learning method

The students were divided into Batch A and Batch B. Batch A and B students attended their practical class scheduled on Tuesday and Thursday respectively.

Week 1 of the experiment-all students of two batches were given demonstration in their respective practical classes. The batches were further divided into five small groups for better dissemination of knowledge. Demonstration to these smaller groups was given by five different faculties. The faculties showed different steps for setting up a hand mannequin, identification of common medical devices used for intramuscular injection, intravenous infusion, parts of the syringe, and needle. IM injection and IV infusion techniques were also demonstrated in a stepwise manner. A handout containing 
all the reading materials was also given to each student for better understanding.

Week 2-OSPE evaluation was done only of those students who were present in the first week [(Batch A (39)+batch B (41) = Total students $(\mathrm{N}=80)]$.
After a month, all the students who were present in the first two weeks of experiment $(\mathrm{N}=80)$ were again given a demonstration of the same thing. This time, powerpoint explanation (intervention) was given prior to demonstration. Following week, OSPE evaluation was conducted for them.

Table 1: Following week, OSPE evaluation was conducted for them

\begin{tabular}{llll}
\hline Students & Week 1 & Week 2 & After a month \\
\cline { 2 - 4 } & & Week 1 \\
$\begin{array}{llll}\text { 2nd Year MBBS students N=80 was included as } \\
\text { they were present in all the classes. }\end{array}$ & $\begin{array}{l}\text { Only Demonstration } \\
\text { teaching }\end{array}$ & $\begin{array}{l}\text { OSPE } \\
\text { evaluation }\end{array}$ & $\begin{array}{l}\text { Demonstration with powerpoint } \\
\text { teaching (intervention) method) }\end{array}$ \\
\hline
\end{tabular}

\section{Development of OSPE stations and allocation of students}

Five OSPE stations were arranged, each station was assigned an observer. Validated checklists were provided at each station, which were evaluated by the faculty at the time of the student's performance. Students were randomly sent to each station and responses were observed and recorded on the checklist for valuation. There was one checklist each for-a) identification of common medical devices used for IM and IV infusion b) parts of a syringe, needle and IV infusion set and c) steps to be followed while performing these injection techniques.

\section{Data recording}

On the day of OSPE evaluation, students were asked to identify parts of syringe, needle, IV infusion set and perform IM injection and IV infusion. Faculties were asked to assign a point (1) for every correct step. Zero (0) was assigned for every missed step. Students were also asked to put their feedback about the OSPE tool on a feedback form.

\section{Data handling and analysis}

Initial feeding and cleaning of data was done in Excel. It was then imported and analysed using SPSS 20.0.0, IBM Corporation and its licensors 1989, 2011. Descriptive frequency analysis was run for all the parameters. Frequencies are expressed in numbers and percentage. Mean OSPE scores of standard and intervention method of teaching were expressed as mean \pm standard deviation and compared using paired sample t-test. A p-value of $<0.05$ was considered as statistically significant.

\section{RESULTS}

Out of total 147 eligible study participants of IInd year MBBS students, responses of only those participants $(\mathrm{N}=80)$ were recorded who had attended all the training and evaluation sessions of OSPE. The responses of 67 participants were not recorded as they were absent in one or more training/evaluation sessions.

We studied the participant's basic knowledge regarding the identification of medical devices, parts of IV set, and syringe. Correct identification of medical devices used in injection techniques (IM, IV infusion) was improved post-intervention (demonstration with PowerPoint explanation) (fig. 1). All participants (100\%) could accurately identify the needle, cannula, and IV infusion bottle. Likewise, correct identification of parts of a syringe (fig. 2) and IV infusion set (fig. 3) were also enhanced post-intervention except for "plunger" (fig. 2).

Steps (executed or NOT executed) for IM injection technique (table 2) and IV (table 3) infusion technique were also evaluated using the OSPE method. Steps were more accurately executed and in sequence post-intervention except for the step "wearing gloves" which remained unchanged (table 2) and "connect leur" (table 3), which was diminished.

The outcome of the paired-sample t-test indicates that there was a statistically significant improvement in the score following intervention in comparison to a standard method in all the tested variables (table 4).

All participants acceded that the OSPE is a fairer, creative, focused, effective, and interesting way of evaluating practical knowledge. More than $90 \%$ of participants opined that OSPE based evaluation has little or no influence of luck, gender, and personality. They also believed that this method was helpful in decreasing anxiety and improving confidence while injecting and should replace the traditional ways of evaluating practical skills (table 5).

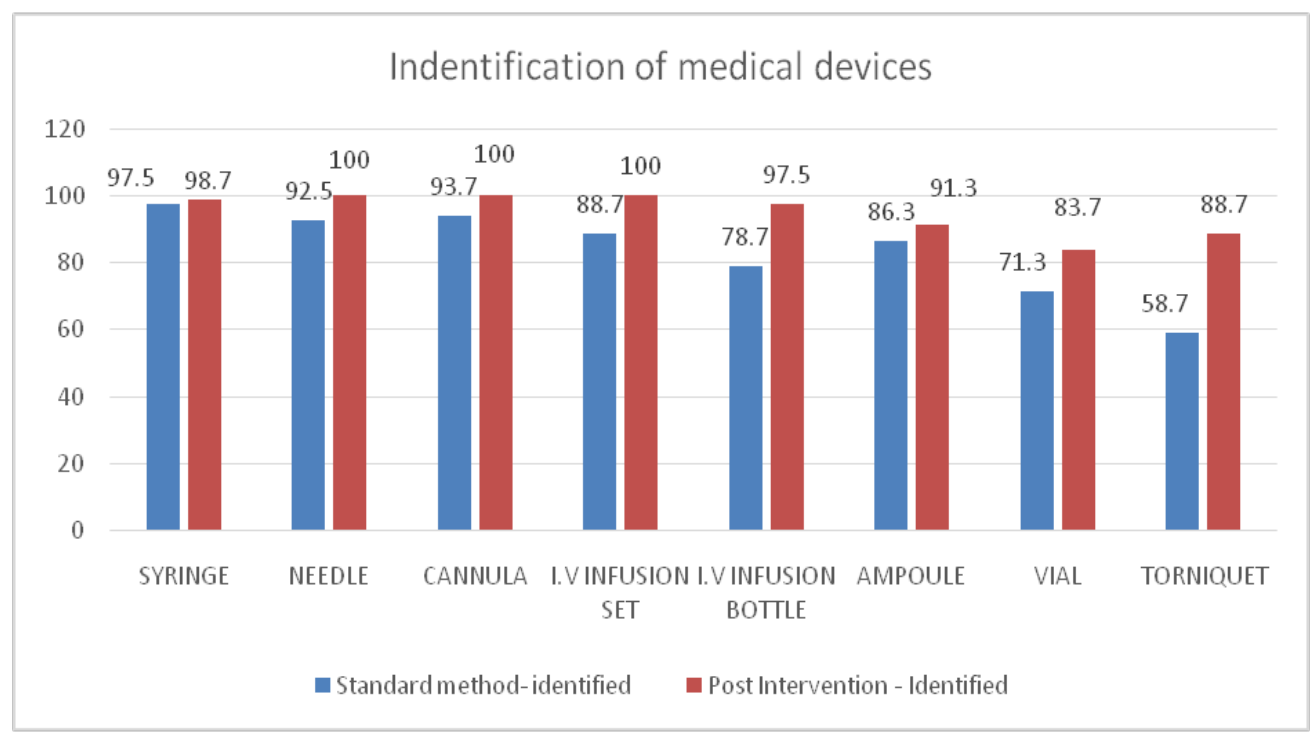

Fig. 1: Percentage of participants who could correctly identify medical devices used in IM and IV infusion technique 


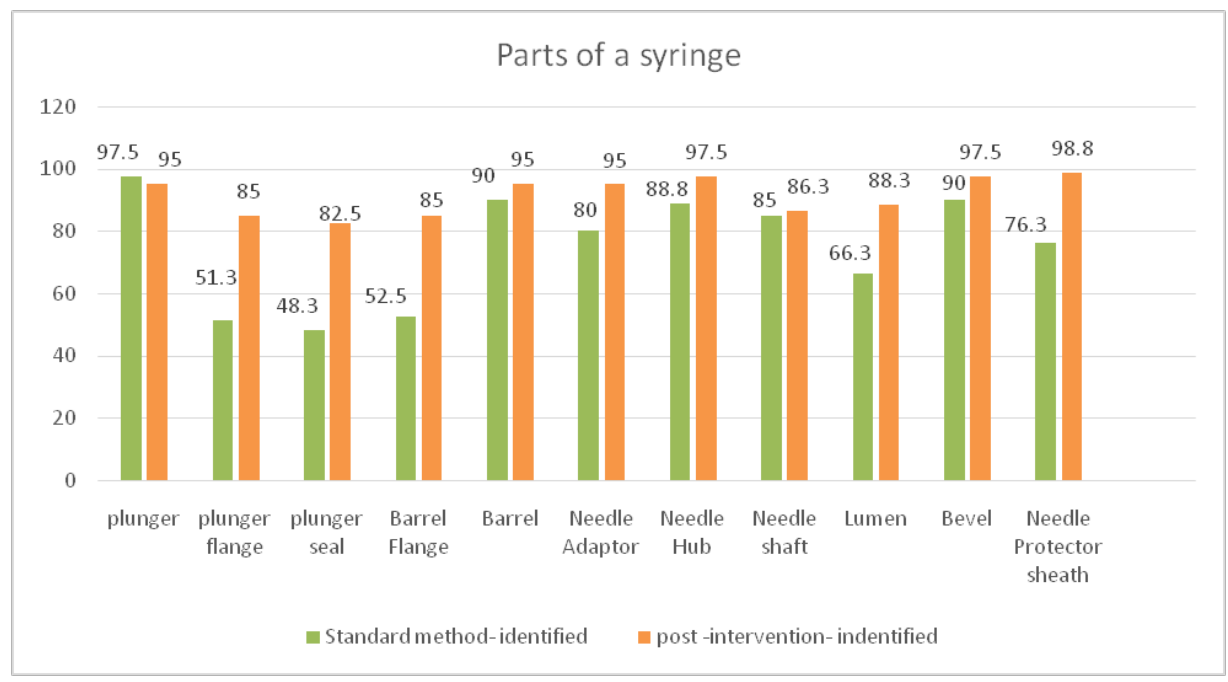

Fig. 2: Percentage of participants who could correctly identify parts of a syringe

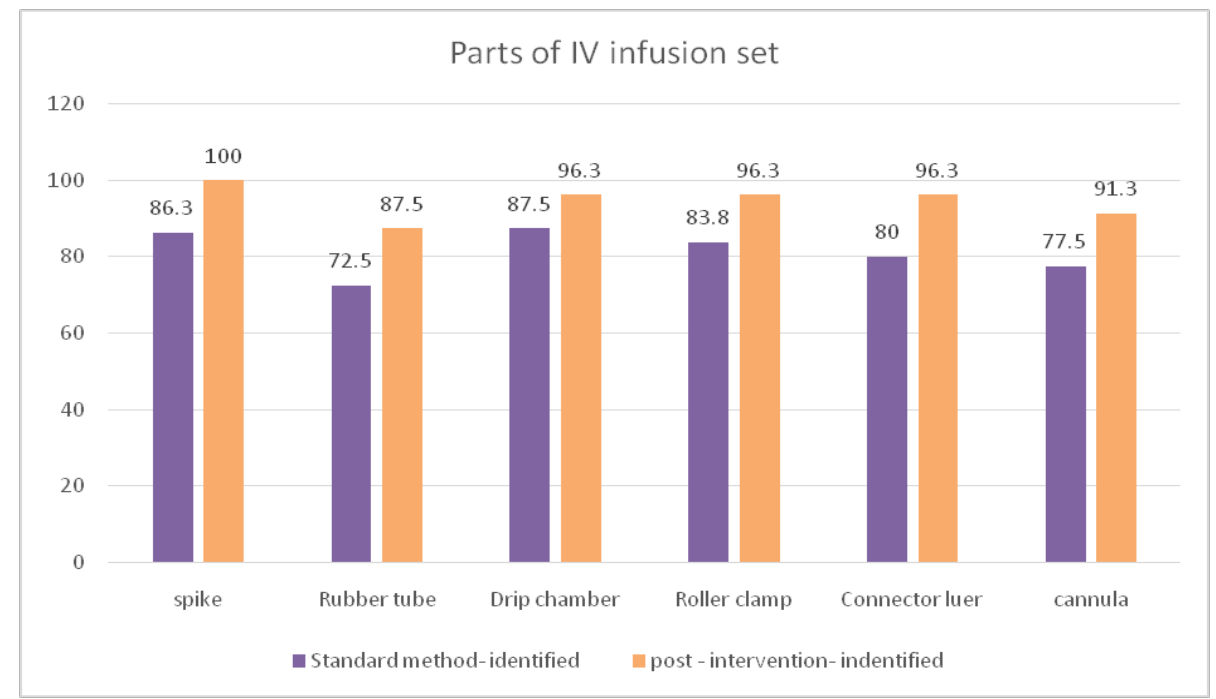

Fig. 3: Percentage of participants who could correctly identify parts of an IV infusion set

Table 2: Steps for IM Injection

\begin{tabular}{lllll}
\hline Steps & Standard (N=80) & & \multicolumn{2}{l}{ Post intervention (N=80) } \\
\cline { 2 - 5 } & Performed (\%) & Not-performed (\%) & Performed (\%) & Not-performed (\%) \\
\hline Crosscheck medicines & $23(28.8)$ & $57(71.3)$ & $78(97.5)$ & $2(2.5)$ \\
Unpack medicines/devices & $42(52.5)$ & $38(47.5)$ & $73(91.3)$ & $7(8.8)$ \\
Check the contents & $39(48.8)$ & $41(51.3)$ & $72(90)$ & $8(10)$ \\
Hand wash & $16(20)$ & $64(80)$ & $69(86.3)$ & $11(13.8)$ \\
Wear gloves & $16(20)$ & $64(80)$ & $16(20)$ & $64(80)$ \\
Load syringe & $64(80)$ & $16(20)$ & $75(93.8 \%)$ & $5(6.3)$ \\
Put the needle protective cover back & $40(50)$ & $40(50)$ & $56(70)$ & $24(30)$ \\
Remove trapped air bubble & $29(36.3)$ & $51(63.8)$ & $49(61.3)$ & $31(38.8)$ \\
Position hand mannequin & $36(45)$ & $44(55)$ & $59(73.8)$ & $21(26.3)$ \\
Locate injection site & $72(90)$ & $8(10)$ & $75(93.8)$ & $5(6.3)$ \\
Preparation of area with antiseptic & $73(7)$ & $91.3(8.8)$ & $78(97.5)$ & $2(2.5)$ \\
Wiping the area in circular motion & $52(65)$ & $28(35)$ & $75(93.8)$ & $5(6.3)$ \\
Administer injection at 90 & $72(90)$ & $8(10)$ & $78(97.5)$ & $2(2.5)$ \\
Keep the bevel up & $18(22.5)$ & $62(77.5)$ & $32(40)$ & $48(60)$ \\
Check for blood aspiration & $31(38.8)$ & $49(61.3)$ & $62(77.5)$ & $18(22.5)$ \\
Withdraw needle at the same angle & $69(86.3)$ & $11(13.8)$ & $78(97.5)$ & $2(2.5)$ \\
Put cotton & $29(36.3)$ & $51(63.8)$ & $61(76.3)$ & $19(23.8)$ \\
Place back the needle sheath & $41(51.3)$ & $39(48.8)$ & $63(78.8)$ & $17(21.3)$ \\
Dispose of the unit safely & $38(47.5)$ & $42(52.5)$ & $68(85)$ & $12(15)$ \\
TheSteps followed in sequence & $12(15)$ & $68(85)$ & $29(36.3)$ & $51(63.8)$ \\
\hline
\end{tabular}


Table 3: Steps for IV infusion

\begin{tabular}{|c|c|c|c|c|}
\hline \multirow[t]{2}{*}{ Steps } & \multicolumn{2}{|l|}{ Standard $(\mathrm{N}=\mathbf{8 0})$} & \multicolumn{2}{|c|}{ Post intervention $(\mathrm{N}=\mathbf{8 0})$} \\
\hline & Performed (\%) & Not-performed (\%) & Performed (\%) & Not-performed (\%) \\
\hline Crosscheck medicines & $17(21.3)$ & $63(78.8)$ & $72(90)$ & $8(10)$ \\
\hline Unpack medicines/devices & $38(47.5)$ & $42(52.5)$ & $69(86.3)$ & $11(13.8)$ \\
\hline Check the contents & $32(40)$ & $48(60)$ & $69(86.3)$ & $11(13.8)$ \\
\hline Hand wash & $7(8.8)$ & $73(91.3)$ & $64(80)$ & $16(20)$ \\
\hline Wear gloves & $10(12.5)$ & $17(87.5)$ & $63(78.8)$ & $17(21.3)$ \\
\hline Tighten theroller clamp & $31(38.8)$ & $49(61.3)$ & $71(88.8)$ & $9(11.3)$ \\
\hline Open and pierce the IV bottle & $40(50)$ & $40(50)$ & $63(78.8)$ & $17(21.3)$ \\
\hline Position hand mannequin & $19(23.8)$ & $61(76.3)$ & $57(71.3)$ & $23(28.8)$ \\
\hline Locate injection site & $37(46.3)$ & $43(53.8)$ & $77(96.3)$ & $3(3.8)$ \\
\hline Preparation of area with antiseptic & $58(72.5)$ & $22(27.5)$ & $70(87.5)$ & $10(12.5)$ \\
\hline Wiping the area in circular motion & $46(57.5)$ & $34(42.5)$ & $60(75)$ & $20(25)$ \\
\hline Administer the injection at $10-25^{\circ}$ & $70(87.5)$ & $10(12.5)$ & $74(92.5)$ & $6(7.5)$ \\
\hline Keep the bevel up & $20(25)$ & $60(75)$ & $36(45)$ & $44(56)$ \\
\hline Check for Flash of blood & $38(47.5)$ & $42(52.5)$ & $72(90)$ & $8(10)$ \\
\hline Remove needle & $50(62.5)$ & $30(32.5)$ & $68(85)$ & $12(15)$ \\
\hline Connect leur connector with cannula & $68(85)$ & $12(15)$ & $62(77.5)$ & $11(22.5)$ \\
\hline Apply the fixator & $20(25)$ & $60(75)$ & $56(70)$ & $24(30)$ \\
\hline Adjust roller clamp & $39(48.8)$ & $41(51.3)$ & $54(67.3)$ & $26(32.5)$ \\
\hline Dispose of the unit safely & $15(18.8)$ & $65(81.3)$ & $46(57.5)$ & $34(42.5)$ \\
\hline TheSteps followed in sequence & $12(15)$ & $68(85)$ & $24(30)$ & $56(70)$ \\
\hline
\end{tabular}

Table 4: Paired sample t-test-comparison of mean objective structured practical examination (OSPE) scores of standard and intervention method

\begin{tabular}{lllll}
\hline Variable & Mean & SE of mean & SD & Sf \\
\hline Identification of medical devices & 0.925 & 0.162 & 1.448 & 79 \\
Parts of a syringe & 1.813 & 0.237 & 2.123 & 79 \\
Parts oftheinfusion set & 0.800 & 0.177 & 1.586 & 79 \\
Steps in IM injection & 5.875 & 0.362 & 3.235 & 79 \\
Steps in IV infusion & 6.850 & 0.369 & $<.001^{*}$ & $<0.001^{*}$ \\
\hline
\end{tabular}

${ }^{*} P$ is $<0.05$; paired samples $t$-test used for analysis. SE of Mean-Standard Error of Mean; SD-Standard Deviation; df-degree of freedom; SigSignificance

Table 5: Feedback

\begin{tabular}{|c|c|c|c|}
\hline S. No. & Variable & $\begin{array}{l}\text { Yes; frequency } \\
\text { (percentage) }\end{array}$ & $\begin{array}{l}\text { No; frequency } \\
\text { (percentage) }\end{array}$ \\
\hline 1 & $\begin{array}{l}\text { OSPE is a fair and improved way of evaluating the understanding of skills related practical } \\
\text { topics(concepts and applications) }\end{array}$ & $80(100)$ & $0(0)$ \\
\hline 2 & $\begin{array}{l}\text { Is OSPE helpful in decreasing your anxiety of causing patient harm and improving your } \\
\text { confidence while performing injection techniques? }\end{array}$ & $78(97.5)$ & $2(2.5)$ \\
\hline 3 & $\begin{array}{l}\text { Whether OSPE based practical classes helped to relate theoretical and practical aspect of } \\
\text { practical topics. }\end{array}$ & $80(100)$ & $0(0)$ \\
\hline 4 & $\begin{array}{l}\text { OSPE is a reliable way of evaluating which decreases the luck factor and there is no bias (effect of } \\
\text { mood on examiner) in grading as it involves step-wise checklist. }\end{array}$ & $76(95)$ & $4(5)$ \\
\hline 5 & It serves the dual function of evaluation both knowledge and skill in single setup. & $79(98.8)$ & $1(1.3)$ \\
\hline 6 & Variables like personality and gender do not affect OSPE score & $76(95)$ & $4(5)$ \\
\hline 7 & Do you agree that OSPE based practical classes is a creative way of learning practical skills?. & $80(100)$ & $0(0)$ \\
\hline 8 & OSPE is more focused, effective and interesting approach & $80(100)$ & $0(0)$ \\
\hline 9 & We felt less fear of examiners in OSPE & $60(75)$ & $20(25)$ \\
\hline 10 & It is physically tiring and stressful & $9(11.3)$ & $71(88.8)$ \\
\hline 11 & OSPE based evaluation is easier to score than traditional practical examination. & $74(92.5)$ & $6(7.5)$ \\
\hline 12 & $\begin{array}{l}\text { Should traditional classes be replaced with OSPE based classes for skill-related practical topics } \\
\text { as a regular way of Teaching? }\end{array}$ & $78(97.5)$ & $2(2.5)$ \\
\hline 13 & $\begin{array}{l}\text { Should the traditional evaluation pattern be replaced by OSPE based evaluation pattern for skill } \\
\text { related practical topics as regular way of evaluation? }\end{array}$ & $77(96.3)$ & $3(3.8)$ \\
\hline
\end{tabular}

\section{DISCUSSION}

According to the new competency-based curriculum for undergraduate medical education, there has been increasing interest in simulation-based learning so as to prevent medication error and ensure patient safety [6]. In the education of undergraduate medical students, simulation appears to be valid, facilitates the achievement of clinical reasoning skills, and minimizes clinical risk for the patient [7]. The objective of this research was to assess the knowledge of medical devices and skills of injection technique (IM/IV infusion) on mannequins using the OSPE method and to compare the effectiveness of two teaching methods.

An upsurge in the knowledge of identifying different medical devices and their parts post-intervention could not be compared with other studies since this was the first time that anyone had studied the knowledge about identification of medical devices, parts of IV set and parts of a syringe among medical undergraduates. 
On head to head comparison of the result of our study with another study[8] we found that after only the demonstration method our study showed that $71 \%, 80 \%, 20 \%, 64 \%, 10 \%, 9 \%, 10 \%$, and $52 \%$ participants did not crosscheck the drugs with that of prescription before administering, did not sanitize hand, did not load the syringe, failed to remove trapped air, forgot to locate the site, did not prepare the site, failed to insert the needle at a proper angle, and failed to do safe disposal respectively, whereas the result of the said study[8] showed $31 \%, 2 \%, 31 \%, 15 \%, 7 \%, 6 \%, 18 \%$ and $10 \%$ for the same steps. In the present study, there was a marked improvement in the percentage of participants failing at executing the above steps after demonstration with the PowerPoint explanation method. Failing to perform these steps properly may lead to the administration of wrong drug and dosage, infection, decreased bioavailability, and tissue/vessel damage. This suggests that the latter method of teaching and training was better and provided effective outcomes. Later student's insights regarding OSPE based evaluation were analyzed. There was marked difference between the result of present and prior studies [9-11] for many variables. In earlier research, only 55\% [9], 21\% [10], 50\% [12] participants reported lesser anxiety and improved confidence while injecting, which was far less in comparison to the current study (98\%).

In the previously done studies around $75 \%[9,13]$ participants found OSPE as a fair method of assessment and $50 \%$ [9] participants had described it as a non-biased (luck, gender, personality) approach for evaluation. This was enormously lesser than our result, $100 \%$ and $95 \%$ respectively. On the other hand, the result of other studies recorded more than $85 \%[11,14]$ participants who tagged OSPE as a non-biased approach which was similar to the result of our study (95\%).

Physically less tiring was yet another variable which we compared with other studies. Only around $30 \%[9,11,15]$ participants had reported OSPE as a less tiring method. Our study reported a higher percentage of $89 \%$ similar to Kriti et al. 78\% [13].

OSPE based approach was found to be "easier to score" than traditional practical examination in the present study (93\%) and other studies-78\% [11], 99\% [13].

Also, similar to the result of this study (97\%) other studies also reported the feedback of participants where the majority $[11,14,16,17]$ opined to displace the traditional methods of teaching and evaluation with that of mannequin based teaching and OSPE based evaluation. In contradiction, the study of Yaquinuddin et al. [18] 74\% of participants preferred to be assessed through a combination of different modes in addition to OSPE. Increased acceptance and enactment of OSPE in recent years may have influenced the drastic shift in the result of the present study compared to the aforementioned studies. In our research, $98 \%$ of participants were in view of switching traditional methods of teaching practical skills with that of simulation-based teaching, which shows that students have more inclination in this type of teaching method and they found simulation-based teaching as an effective method.

The above findings of this study determine that students acquire and perform injection techniques better through demonstration and powerpoint when compared to demonstration alone. These findings were similar to the study [9], which concluded that students attain better skills through teaching than merely watching the videos of these skills.

The Present study evidently indicates that the OSPE based evaluation method would be a better way to assess skills-related practical topics and we might accept that demonstration along with a PowerPoint explanation is an easier method to fill the gap between only theory and only practical skills in comparison to demonstration alone method. Moreover, it is found to be a better way to score more marks.

\section{LIMITATIONS AND STRENGTH}

This study includes the assessment of knowledge of medical devices, parts of a syringe, needle and IV infusion set, which distinguishes it from other studies. This study would be beneficial for newer medical institutions as MCI has stressed on the conduction of OSPE based practical examination pan India. The difference in the way of demonstration of different faculty may have influenced the overall outcome. Since there are no studies to assess the knowledge of identification of medical devices, parts of a syringe, and IV infusion set, the results could not be compared.

\section{CONCLUSION}

The present study highlights the many benefits of mannequin based teaching method and OSPE based evaluation method especially for skills-related practical components. Powerpoint explanation prior to the demonstration was found to be more effective than the traditionally used demonstration method alone. We recommend a combination of both. Once again, OSPE based evaluation method found to be the effective tool for assessing knowledge.

\section{ACKNOWLEDGEMENT}

Nil

\section{FUNDING}

Nil

\section{AUTHORS CONTRIBUTIONS}

Dr. Sunil Kumar Pandey: Conduction of project, data analysis and interpretation, submission revision, Dr. Sarita Panigrahy: Preparation of protocol, manuscript, data input, revision, Dr. Meher Sheena: Data collection and compilation, Mrs. Bala Tripura Sundari: Data collection and compilation

\section{CONFLICTS OF INTERESTS}

\section{Declared none}

\section{REFERENCES}

1. WHO best practices for injections and related procedures tool kit. World health organization. WHO/EHT/10.02; 2010.

2. Gupta E, Bajpai M, Sharma P, Shah A, Sarin S. Unsafe injection practices: a potential weapon for the outbreak of blood-borne viruses in the community. Ann Med Health Sci Res. 2013;3(2):177-81. doi: 10.4103/2141-9248.113657, PMID 23919185, PMCID PMC3728858.

3. Al-Elq AH. Simulation-based medical teaching and learning. J Family Community Med. 2010;17(1):35-40. doi: 10.4103/13191683.68787, PMID 22022669, PMCID PMC3195067.

4. Harden RM, Stevenson M, Downie WW, Wilson GM. Assessment of clinical competence using the objective structured examination. $\mathrm{Br}$ Med J. 1975;1(5955):447-51. doi: 10.1136/bmj.1.5955.447, PMID 1115966, PMCID PMC1672423.

5. Medical Council of India. Competency-based undergraduate curriculum for the Indian Medical Graduate; 2018. p. 1. Available from: http://www.india.mciindia.org/ cms/ information-desk/for-colleges/ug-curriculum. [Last accessed on 21 Sep 2020]

6. Mani S, Nisha M, Varghese J, Johny S, Mathew A. Cost-effective innovation of locally assembled mannequins for undergraduate skill development in parenteral drug administration. Indian J Pharmacol. 2020;52(1):39-43. doi: 10.4103/ijp.IJP_279_19, PMID 32201445.

7. Oliven A, Nave R, Hasson Gilad DR, Baruch A. Medical students' views on the use of virtual patients for teaching and assessment of clinical knowledge and reasoning. Harefuah. 2013;152(5):257-61, 310. PMID 23885447.

8. Bharath Kumar VD, Kalpana L, Veena RM, Lavanya SH, Manasa CR. A study to evaluate injection techniques of medical undergraduates on mannequins in a medical college. Int J Biol Pharm Res. 2015;6:961-4.

9. Devi V, Upadhye P, Ram P, Menezes RG. Development of a teaching module for parenteral drug administration and objective structured practical examination stations in pharmacology. Indian J Pharmacol. 2013;45(6):587-92. doi: 10.4103/0253-7613.121369, PMID 24347766.

10. SHL, LK. Mannequin-based simulation as an educational tool for learning injection techniques: medical students' viewpoints. Int J Basic Clin Pharmacol. 2018;7(5):882-7. doi: 10.18203/2319-2003.ijbcp20181629. 
11. Baral B. Objective structured practical evaluation: Comparison the traditional practical examination and Student's perception. Nepal Med Coll J. 2017;19:84-9.

12. Bashir A, Tahir S, Younus R, Khan JS. Impact of OSPE on students' approach to learning! A qualitative study. Biomedica. 2016;32:206-13.

13. Vishwakarma K, Sharma M, Matreja PS, Giri VP. Introducing objective structured practical examination as a method of learning and evaluation for undergraduate pharmacology. Indian J Pharmacol. 2016;48(Suppl 1):S47-51. doi: 10.4103/02537613.193317, PMID 28031608.

14. Patil AD, Gaikawad AP, Shriram VD, Baheti BH. Introduction of objective structured practical examination for osteology. MedPulse-international. Med J. 2014;1:43-5.
15. Imani M, Hosseini Tabatabaie MT. Is OSCE successful in pediatrics? J Med Educ Winter. 2005;6:153-8.

16. Rao RD, Babu PU, Chakravarthy KCV, Ramya N. Objective structured practical examination (OSPE) as a tool in formative assessment of II MBBS students in pathology. Int J Res Med Sci. 2018;6:221-4.

17. Chandelkar UK, Rataboli PV, Samuel LJ, Kamat AS, Bandodkar LV. Objective structured practical examination: our experience in pharmacology at. Vol. 1. Bambolim, Goa, India: Goa Medical College. Int J Sci Rep; 2015. p. 113-7.

18. Yaqinuddin A, Zafar M, Ikram MF, Ganguly P. What is an objective structured practical examination in anatomy? AnatSciEduc 2013;6:125-33. 